Literatura y Lingüística $\mathrm{N}^{\circ} 25$

ISSN 0716-5811 / pp. 121-143

\title{
Evaluación de la puesta en marcha del enfoque metodológico por competencias comunicativas FOCAL SKILLS*
}

\author{
Yasna Angélica Yilorm Barrientos ** \\ Andrea Bárbara Alicia Lizasoain Conejeros ${ }^{* * *}$
}

\section{Resumen}

En este trabajo se describe el enfoque metodológico por competencias comunicativas FOCAL SKILLS propuesto por Hastings (2007 [1988]) -vinculado al modelo de comunicación de Jakobson (1960) y la teoría de la competencia comunicativa de Chomsky (1965) - y su posible aplicación en la Universidad Austral de Chile como estrategia para mejorar la adquisición del inglés como lengua extranjera por parte de los estudiantes. Además, se describen la metodología de implementación del enfoque y los obstáculos a los que los investigadores se han visto enfrentados, junto con posibles soluciones.

Palabras clave: modelo de comunicación, competencia comunicativa, enfoque metodológico innovador en el aula, FOCAL SKILLS, adquisición de lenguas extranjeras

\section{Evaluation of the Implementation of the FOCAL SKILLS Approach}

\begin{abstract}
This work describes the methodological approach to communicative competence FOCAL SKILLS as proposed by Hastings (2007 [1988]) -an approach that is related to Jakobson's communication model (1960) and to Chomsky's theory of communicative competence (1965) - and considers its possible application within the Universidad Austral de Chile as a strategy for improving acquisition of English as a foreign language by students. This paper also examines the methodology for implementing this approach and the obstacles which the researchers have faced, along with possible solutions.
\end{abstract}

Key words: Communication model, communicative competence, innovating methodological approach in the classroom, FOCAL SKILLS, acquisition of foreign languages

Recibido: 13-12-2011 Aceptado: 29-12-2011

* Investigación "Efectividad del enfoque metodológico por competencias comunicativas "FOCAL SKILLS" en el proceso de adquisición del inglés como lengua extranjera de estudiantes de 6to básico de establecimientos educacionales públicos de la ciudad de Valdivia", perteneciente al programa de Doctorado en Comunicación, Universidad Autónoma de Barcelona, España.

** Master of Science in Education, TESOL concentration, Instituto de Lingüística y Literatura, Facultad de Filosofía y Humanidades, Universidad Austral de Chile, yyilorm@uach.cl

*** Magíster en Adquisición de Segundas Lenguas, Instituto de Lingüística y Literatura, Facultad de Filosofía y Humanidades, Universidad Austral de Chile, andrea.lizasoain@uach.cl 
Evaluación de la puesta en marcha del enfoque metodológico por competencias comunicativas FOCAL SKILLS / Yasna Yilorm y Andrea Lizasoain

\section{Introducción}

En los últimos diez años, en base a los estudios realizados por el programa Inglés Abre Puertas en 2004, el Ministerio de Educación ha afirmado que existen niveles de competencias dispares y deficientes en la asignatura de inglés, entre los alumnos de enseñanza básica y media de la educación pública chilena. Las investigaciones cualitativas y cuantitativas realizadas hasta la fecha en el área de pedagogía en inglés en Chile son escasas, pero apuntan claramente a una crisis profunda en la calidad de la enseñanza y del aprendizaje de esta lengua.

Con el fin de evaluar el dominio de la lengua inglesa en los establecimientos educacionales públicos chilenos, en octubre del 2004, se aplicó una prueba de diagnóstico a 11.000 estudiantes de enseñanza básica y media de 299 escuelas públicas de diferentes regiones y áreas socio-económicas del país. Solo un 5\% de los estudiantes de enseñanza media alcanzó el nivel requerido por el MINEDUC al término de cuarto medio (Ministerio de Educación, 2004); en otras palabras, un muy bajo porcentaje podía comprender las ideas principales de textos familiares relacionados con el trabajo, el colegio o el tiempo libre, o manejarse en situaciones de viaje, competencias clasificadas en el nivel Bl del Marco Común Europeo de Referencia para las Lenguas (CEF) o en el nivel ALTE 2 de la Asociación Europea de Examinadores de Idiomas. Según Andrew Sheehan, asesor británico del programa Inglés Abre Puertas entre 2003 y 2006, la mayoría de los estudiantes obtuvo resultados inferiores a los niveles esperados y, consecuentemente, la entidad examinadora -ESOL Examinations de la Universidad de Cambridge- tuvo que crear dos nuevos niveles que reflejaran particularmente la realidad chilena (citado en Arcos y Poblete, 2009). A su vez, los resultados de la primera prueba SIMCE inglés - una adaptación de la prueba TOEIC Bridge (Test of English for International Communication) de Educational Testing Service (ETS)-, aplicada el último trimestre de 2010 a todos los estudiantes de $3^{\circ}$ medio del país (alrededor de 220.000), apuntaron a lo mismo: solo el 11\% alcanza un nivel básico (B1) de esta lengua extranjera (EducarChile, 2011); cabe resaltar que la mayoría de estos estudiantes proviene de establecimientos particulares (La Nación, 2011: §§ 1-6).

Asimismo, se ha observado que un porcentaje significativo de estudiantes de la Universidad Austral de Chile (UACh) no desarrolla del todo las competencias esperadas en las asignaturas de inglés una vez completados los cursos que incluyen sus respectivas mallas curriculares. Los casos de Ingeniería Comercial y Auditoría (carreras con seis y

$+220$


ocho semestres de inglés, respectivamente) son claros ejemplos de esta situación. De acuerdo con los datos proporcionados por la oficina de Registro Académico de la UACh en 2010, entre los años 1993 y 2009, 1.661 alumnos de la carrera de Ingeniería Comercial aprobaron las asignaturas de inglés con un promedio de notas equivalente a un 4,6 (en un rango del 1,0 al 7,0), lo que comúnmente se califica como "suficiente", pero no exitoso. De acuerdo al enfoque FOCAL SKILLS, esto se traduce en una comunicación deficiente, ya que para alcanzar una competencia comunicativa, dicho enfoque requiere que los estudiantes logren un 5,6 (48/60 puntos o un 80\% de logro). Debido a lo anterior, es posible afirmar que el promedio de los estudiantes de Ingeniería Comercial no cumplió en su totalidad con el dominio de competencias esperadas de acuerdo a este enfoque. En cuanto a la carrera de Auditoría, entre los mismos años, 2.799 alumnos cursaron las asignaturas de inglés con un promedio de notas equivalente a un 4,7. Por lo tanto, se refleja la misma realidad que en la carrera de Ingeniería Comercial.

Dentro de las causas posibles de este bajo dominio de competencias, se encuentra que Chile no es un país bilingüe donde el inglés se pueda adquirir como segunda lengua. Muy por el contrario, el inglés se enseña como lengua extranjera, lo cual limita considerablemente el contacto directo y auténtico con dicha lengua. La clase de inglés resulta ser la principal y, en muchos casos, única instancia en que los estudiantes se ven expuestos a este idioma, lo que implica, por un lado, que estos desarrollan un aprendizaje consciente, sin adquirir la lengua. Al respecto, Krashen (1998) explica que es el conocimiento adquirido inconscientemente el que conduce a la adquisición de la lengua. Por otra parte, los estudiantes tienen pocas instancias de comunicación real en las que pueda activarse el modelo de comunicación de Jakobson, lo que dificulta el desarrollo de sus competencias comunicativas. A este problema también se suma la escasez de material auténtico en las aulas chilenas, todo lo cual no contribuye a un proceso de adquisición de índole natural.

Por otra parte, el final del siglo XX enfrentó a la educación con una serie de cambios e innovaciones, entre los que se destacan la inclusión de nuevas tecnologías y

un nuevo escenario social: globalización financiera, desarrollo del comercio internacional, presión de corte neoliberal sobre el Estado de bienestar, la deslocalización de la producción y el imaginario consumista de una sociedad en que la tecnología se ha convertido en el fetiche máximo. En conjunto, un brusco y profundo cambio de circunstancias (Pérez, 2000: 37). 
Evaluación de la puesta en marcha del enfoque metodológico por competencias comunicativas FOCAL SKILLS / Yasna Yilorm y Andrea Lizasoain

Lo anterior ha sorprendido a gran parte de los docentes sin la preparación suficiente para enfrentar y asumir dichos cambios dentro de las aulas.

En relación a esto, en esta investigación se sugiere que la causa principal del bajo dominio de la lengua inglesa, en el contexto de la Universidad Austral de Chile, podría residir en el uso de metodologías basadas en la enseñanza explícita de la gramática y en el apoyo fundamental de textos de estudio, lo que constituiría material didáctico artificial según el enfoque abordado. Además, muchos de los textos de estudio están basados en el aprendizaje de una lengua por medio de estructuras gramaticales y no siempre enseñan la gramática en forma efectiva, rigurosa y comprensible (Hastings y Murphy, 2002: 6).

Este material no auténtico con frecuencia está descontextualizado y resulta poco atractivo y ajeno a la realidad de los estudiantes. Según Logan (citado en Pérez, 2000: 48), los profesores se aferran al antiguo sistema de aprendizaje basado en el texto, ajenos a la era de la información y los estudiantes no le encuentran sentido a la escolarización, todo lo cual lleva a un fracaso en la educación. En la misma línea, Bernabeu (1997) afirma que los profesores se han visto expuestos a

la aparición de un nuevo tipo de alumno, que presenta la característica fundamental de necesitar grandes dosis de motivación para aprender y a quien aburre una explicación teórica tradicional [...]. Es un alumno que se ha socializado en un mundo de imágenes y que se ha "instruido" desde y con la mecánica discursiva del audiovisual. Este alumnado, generación presente y futura de la sociedad mediática exige un replanteamiento en las estrategias pedagógicas y didácticas (citado en Pérez, 2000: 201).

La apertura de Chile al mercado internacional ha generado, a su vez, la urgente necesidad de adquirir competencias comunicativas en la lengua inglesa ${ }^{1}$, lo que ha impactado directamente el aumento de la

1 Lamentablemente, no se ha dado una respuesta efectiva a esta necesidad en el campo de las metodologías de enseñanza-aprendizaje. Por ejemplo, desde los años 80 hasta el presente, solo se han realizado los siguientes proyectos Fondecyt regulares relacionados con el campo que ocupa esta propuesta: "Aplicación de la Suggestopedia al aprendizaje del inglés como lengua extranjera" N. 1851098 (1985, Miguel Ángel Farías); "Determinación del grado de persistencia de destrezas docentes adquiridas en dos programas de entrenamiento, uno con una micro-enseñanza y otro con enseñanza reflexiva en alumnos terminales de las carreras de pedagogía en inglés y francés" N. 1910377 (1991, María Valderrama Reyes); "El sistema de cognición docente, las actuaciones pedagógicas del profesor inglés universitario y su impacto en la enseñanza-aprendizaje del idioma” N. 1085313 (2008, Claudio Díaz Larenas); y

124


demanda de asignaturas de inglés en la Universidad Austral de Chile. Según datos entregados por el Centro de Idiomas de esta universidad en 2010, en el año 2009, se contabilizaron 1.653 estudiantes de las carreras de la UACh con necesidad de cursar la asignatura de inglés para complementar su formación académica con nuevas competencias. En consecuencia, se ha tornado indispensable intervenir urgentemente con proyectos innovadores y con "un modelo metodológico de comunicación educativa al servicio del desarrollo y del cambio social" (Sierra, 2002: 20), que suplan las necesidades, propósitos y requerimientos actuales de los estudiantes del siglo XXI, como es el caso de la aplicación del enfoque metodológico por competencias comunicativas FOCAL SKILLS. $\mathrm{Al}$ respecto, un número importante de estudios ha demostrado que los estudiantes expuestos a este enfoque logran un 35\% más de habilidad para comunicarse en inglés en un semestre, en comparación con aquellos estudiantes pertenecientes a otros tipos de programas de segunda lengua (Global Language Education Services, 2010), lo que podría extenderse a los programas de enseñanza de lenguas extranjeras.

En el contexto chileno, durante el segundo semestre del año 2007 se realizó un estudio piloto con cuatro cursos de 25 estudiantes en promedio de diferentes carreras de la Universidad Austral de Chile (Ingeniería Comercial, Turismo, Leyes y Pedagogía en Comunicación en Lengua Inglesa). Estos fueron expuestos a metodologías de enfoque comunicativo y a material didáctico innovador (promovidos por el enfoque metodológico FOCAL SKILLS). No se consideraron los módulos por competencias comunicativas que constituyen el enfoque (Listening, Reading, Writing y Advanced), los cuales se explicarán más adelante. A través de encuestas de opinión, el estudio reveló que, en su totalidad, los estudiantes $(\mathrm{N}=57)$ experimentaron un alto grado de satisfacción académica y de reencantamiento con el proceso de enseñanza-aprendizaje de la lengua inglesa. El estudio arrojó un cambio de actitud hacia la asignatura y una apreciación positiva del uso de metodologías innovadoras y materiales didácticos atractivos, la participación activa de todos los estudiantes, la calidad humana y empatía del profesor, el alto nivel de comprensión y aprendizaje de los contenidos por parte de los estudiantes y la reafirmación de valores que contribuyen a su formación integral.

En el presente trabajo, se evaluará la puesta en marcha de un proyecto para medir la efectividad del enfoque metodológico por competencias

"Comprensión de textos académicos escritos en inglés. Hacia un perfil multidimensional en dos ámbitos disciplinares” N. 10853113 (2006, Romualdo Ibáñez Orellana). 
Evaluación de la puesta en marcha del enfoque metodológico por competencias comunicativas FOCAL SKILLS / Yasna Yilorm y Andrea Lizasoain

comunicativas FOCAL SKILLS de Hastings (2007 [1988]) al aplicarlo a los estudiantes de las carreras de Ingeniería Comercial de primer año (grupo experimental), en comparación con la inclusión de prácticas basadas en la enseñanza explícita de reglas gramaticales con estudiantes de segundo año de Auditoría (grupo control) de la Universidad Austral de Chile. Específicamente, se busca poner en evidencia que el enfoque FOCAL SKILLS incentivaría en los estudiantes el fenómeno de "competencia comunicativa", lo que conduciría a la adquisición natural del inglés como lengua extranjera. A su vez, se expone el diseño e implementación de una versión adaptada del Módulo 1 de comprensión auditiva del enfoque -que se explicará más adelante- para estudiantes de las carreras de Ingeniería Comercial de la Universidad Austral de Chile.

\section{Competencia comunicativa y lengua extranjera}

Actualmente, y respondiendo a los cambios sociales a nivel mundial, el ideal de todo profesor de inglés es que los estudiantes adquieran una competencia comunicativa que les permita comunicarse, efectivamente, en la lengua extranjera y así lograr sus metas personales y/o profesionales. Para lograr dichos objetivos, se sugiere integrar a la propia realidad el modelo comunicativo de Jakobson (1960), con el fin de que el mensaje enviado por el hablante llegue a su destinatario de la mejor manera posible. Las prácticas de enseñanza-aprendizaje que facilitan la integración de ese modelo a la comunicación promueven la adquisición de una competencia comunicativa más efectiva. Uno de los ejemplos que mejor reflejan estas prácticas es el enfoque FOCAL SKILLS.

En 1965, Chomsky diferenció el concepto de "competencia gramatical" con el de "actuación" (Yano, 2002: 1), dos términos lingüísticos que darían posterior origen al concepto de "competencia comunicativa" (Hymes, 1992, citado en Richards \& Rogers, 2001: 159) como un solo elemento capaz de fusionar los conocimientos de una lengua con su aplicación. La "competencia gramatical" (competence) dice relación con el conocimiento lingüístico del hablante nativo ideal, el conocimiento del hablante y el oyente acerca de su lengua" (Chomsky, 1965:4) y la "actuación" (performance) consiste en "el uso real de la lengua en situaciones concretas" (ibid). En el contexto de la enseñanza de una segunda lengua, Canale y Swain (1980) sintetizan estos dos conceptos en la noción de "competencia comunicativa", como

una síntesis del conocimiento de los principios gramaticales básicos, de cómo se utiliza el lenguaje en entornos sociales para

-


llevar a cabo las funciones comunicativas y el conocimiento de la manera en que las expresiones y las funciones comunicativas pueden combinarse según los principios del discurso (citado en Yano, 2002: 30),

conduciendo así a nuevos enfoques metodológicos de índole comunicativa que conllevan a la adquisición de la lengua.

Así, el propósito final de la enseñanza del inglés es que los estudiantes desarrollen la competencia comunicativa para lograr participar exitosamente en el mundo real y "comunicarse con éxito significa transmitir un mensaje comprensible al destinatario" (Rababah, 2000: 1). En el marco de Canale and Swain (1980), la competencia comunicativa incluye la competencia gramatical, socio-lingüística, discursiva y estratégica. La competencia gramatical consiste en el dominio del código lingüístico, incluidos el conocimiento léxico, las reglas de pronunciación y escritura, la formación de palabras y la sintaxis de la lengua (Omaggio, 2001; Brown, 2007). La competencia sociolingüística dice relación con las reglas socioculturales de una comunidad; se refiere a cómo una expresión se puede utilizar y comprender apropiadamente en un contexto dado, dependiendo del tema, el papel de los participantes y el entorno (Omaggio, 2001; Brown, 2007; Rababah, 2000) e influye en la elección del estilo y el registro. La competencia discursiva se refiere a la conexión de una serie de oraciones para formar un todo significativo (Rababah, 2000), que es el discurso; "una persona con un alto grado de competencia discursiva sabrá cómo usar elementos de cohesión, como pronombres y conectores gramaticales (es decir, conjunciones, adverbios y frases transicionales) para lograr unidad" (Omaggio, 2001: 6). Y, por último, la competencia estratégica consiste en estrategias comunicacionales verbales y no verbales (Canale, 1983, citado en Rababah, 2000: 2) para compensar brechas comunicacionales en una situación lingüística o "debido a variables de actuación o una competencia insuficiente" (Brown, 2007: 220). A su vez, la propuesta de Bachman (1990, citado en Brown, 2007: 220-221) desarrolla aún más el concepto de competencia comunicativa haciendo referencia, por un lado, a la competencia organizacional, que incluye la competencia gramatical (vocabulario, morfología, sintaxis, fonología y grafología) y la textual (cohesión, organización retórica); y por otro, a la competencia pragmática, que incluye la competencia ilocucionaria (función ideacional, función manipulativa, función heurística, función imaginativa) y la competencia sociolingüística (sensibilidad al dialecto o variedad, sensibilidad al registro, sensibilidad a la naturalidad, referencias culturales y figuras del discurso), acercándose así a un dominio ideal de 
Evaluación de la puesta en marcha del enfoque metodológico por competencias comunicativas FOCAL SKILLS / Yasna Yilorm y Andrea Lizasoain

la lengua que permite una comunicación eficaz entre sus hablantes. Es decir, siguiendo a van Dijk (2008), Bachman considera la competencia comunicativa como un "conocimiento compartido" (p. 37) y, como tal, se puede transmitir de un hablante a otro, del emisor al receptor, del profesor al estudiante. Por este motivo, esta investigación sostiene que incorporando ejercicios y experiencias que desarrollen estas competencias y subcompetencias en la sala de clases a través de prácticas comunicacionales, los estudiantes pueden alcanzar la competencia comunicativa necesaria para producir mensajes y comprenderlos, eficazmente, en la lengua extranjera, con la ayuda del profesor.

\subsection{Prácticas comunicacionales}

Más que las prácticas tradicionales basadas en la traducción y en la instrucción explícita de reglas gramaticales -como los métodos GramáticaTraducción y Audiolingüe- los enfoques comunicacionales han demostrado ser poderosas herramientas para enseñar y adquirir una lengua extranjera, ya que proveen a los profesores y estudiantes de múltiples espacios de expresión y oportunidades para interactuar en forma natural e inconsciente. "La enseñanza de carácter comunicativo hace uso de situaciones de la vida real que requieren de la comunicación genuina. El profesor presenta a los estudiantes situaciones que van a encontrar en la vida real" (Galloway, 1993: 1).

Para que los alumnos alcancen niveles adecuados de competencia comunicativa, se sugiere cumplir con los principios propuestos por expertos como Krashen (1985) y Terrel (1983), autores del Método Natural. De acuerdo a este, en primer lugar, además de estar expuestos a actividades de índole comunicativa, los estudiantes deben adquirir la lengua extranjera gradualmente, partiendo por un "periodo de silencio" necesario para observar y especialmente escuchar, al igual que lo hacen los niños cuando adquieren su lengua materna. "Es necesario comprender antes de producir" (Richard-Amato, 2003: 170). De esta manera, los estudiantes deben estar expuestos a mensajes que puedan entender, ya que la decodificación de significados es una prioridad. En segundo lugar, el aprendizaje de las estructuras gramaticales ha de alcanzarse en forma implícita, lo que significa que los profesores deben enseñar las estructuras gramaticales a través de situaciones contextualizadas y atractivas (reales) que conduzcan a un proceso de adquisición inconsciente (Krashen, 1985). Además, como factor contribuyente a una adquisición efectiva, se sugiere que los estudiantes se sientan interesados, seguros

y tranquilos en la sala de clase, debido a que el proceso de adquisición

-


de una lengua extranjera está estrechamente ligado a la identidad y desarrollo emocional de cada individuo. Mientras más se comprenda un mensaje, menores son los niveles de ansiedad y de temor al estar inmerso en un ambiente nuevo donde la principal herramienta de comunicación, que es la lengua, es diferente e incomprendida (Ariza, Morales-Jones, Yahya y Zainuddin, 2002).

\subsection{Modelo de la comunicación de Jakobson}

Con el fin de que, a su vez, se cumplan los principios básicos de las prácticas comunicacionales mencionados anteriormente, y de manera que la comunicación entre el profesor y el estudiante y entre los estudiantes mismos sea eficaz, es necesario que los mensajes enviados se traspasen de manera fluida desde el destinador hasta el destinatario, como ocurre en el modelo de la comunicación de Jakobson (1960). De acuerdo a Rodrigo Alsina, el aporte de Jakobson a los modelos de comunicación se refleja en su artículo Lingüística y poética de 1960, donde el autor analiza las funciones del lenguaje (1995: 65). Su primera contribución consiste en postular el siguiente modelo de comunicación, en el que hace referencia a los factores que componen la comunicación verbal. Jakobson adjudica a cada factor una función, originándose así el siguiente esquema:

Esquema 1. Modelo de la comunicación de Jakobson (1960)

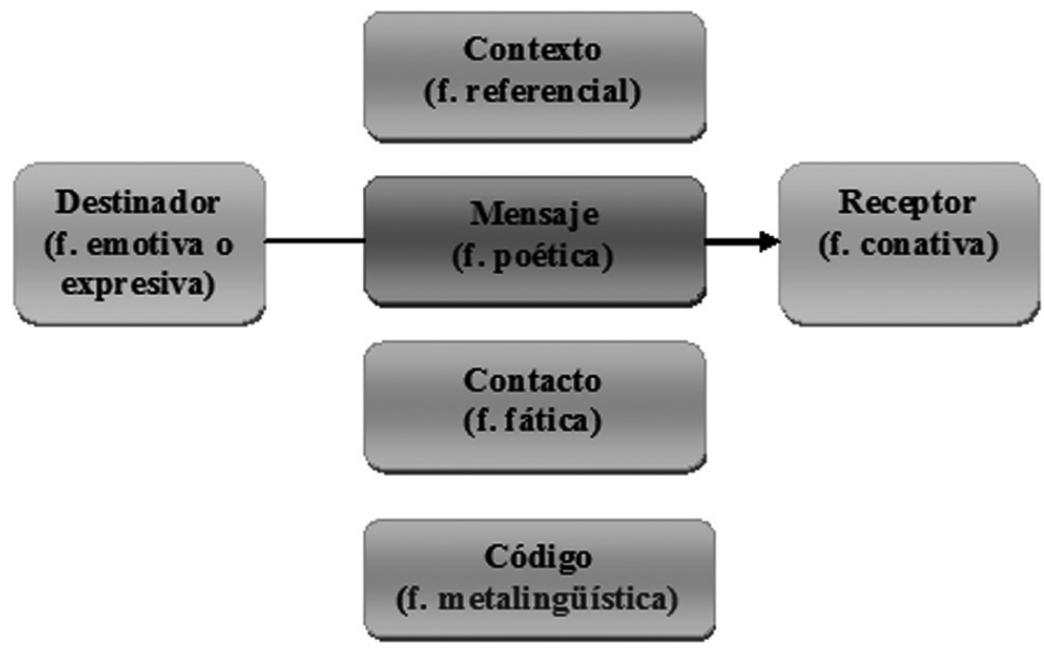

Rodrigo Alsina explica que el mensaje, elemento esencial de la comunicación, es transmitido al destinatario por parte del destinador dentro de un contexto que sirve de referencia para su interpretación. Además, para que el mensaje se entienda, es necesario un código común entre el destinador y el destinatario, para poder codificar y luego decodificar el mensaje. Finalmente, el contacto, que para Jakobson es "un canal físico 
Evaluación de la puesta en marcha del enfoque metodológico por competencias comunicativas FOCAL SKILLS / Yasna Yilorm y Andrea Lizasoain

y una conexión psicológica entre el destinador y el destinatario, [...] permite tanto al uno como al otro establecer y mantener una comunicación" (1975a: 352, citado en Rodrigo Alsina, 1995: 65).

\subsubsection{Funciones del Lenguaje}

La función referencial, denotativa o cognoscitiva, se refiere al contexto, apunta específicamente a la información y es de carácter objetivo. La función emotiva o expresiva se ubica junto al destinador debido a que señala su actitud y/o lo que siente y se define según las relaciones entre el destinador y el mensaje (Rodrigo Alsina, 1995: 66). Los elementos prosódicos, la entonación y la melodía actúan como elementos productores de la función emotiva. La función conativa es de carácter exhortativa y su propósito es lograr una reacción por parte del receptor. El vocativo, la oración imperativa y la interrogativa son expresiones gramaticales de esta función. La función fática se manifiesta a través de expresiones que cumplen el objetivo "de establecer, prolongar o interrumpir la comunicación" (ibid.). Asegura que el canal de comunicación esté funcionando apropiadamente a través de fórmulas (de saludo, despedida, etc.), de modo que exista comunicación entre el destinador y el receptor. La función metalingüística dice relación con "la elección de un determinado código" (p. 67) y su misión es comprobar que los participantes del evento comunicativo estén utilizando el mismo código lingüístico. Finalmente, la función poética se centra en el mensaje mismo. Aunque los mensajes poéticos sean los más representativos de esta función, no necesariamente tiene que ver con la literatura exclusivamente. La rima y la aliteración son ejemplos de expresiones de esta función, los que pueden darse en el lenguaje coloquial también.

Llevado a la sala de clases, el modelo funciona de la siguiente manera: el destinador (profesor) tiene como propósito enviarle al receptor (alumno) un mensaje, que no puede ser interpretado si no es dentro de un contexto, si no se comunica en un código común entre el destinador y el receptor, ni si el contacto o canal de comunicación no es fluido.

\section{El modelo de la comunicación de Jakobson y el enfoque metodológico FOCAL SKILLS}

Un factor importante en el modelo de comunicación de Jakobson es el receptor, el que, bajo este enfoque, es un aprendiz de inglés como lengua extranjera. "El paso del concepto de "receptor" a "destinatario" es

$+130$


crucial, porque, mientras que el receptor puede ser cualquiera que reciba el mensaje, el destinatario es aquél al que el destinador ha elegido como su receptor" (Rodrigo Alsina, 1995: 69). Por ende, el profesor de inglés debe preocuparse de que el mensaje llegue a su receptor, es decir, a su alumno, de la mejor manera posible. Rodrigo Alsina sigue a Jakobson y le da gran importancia a los resultados del mensaje -"cualquier conducta verbal tiene un propósito" (Jakobson, 1967: 29)-, un asunto del que los científicos del lenguaje se ocupan cada día más.

Se logra, así, un vínculo con la pragmática de la comunicación, asegurándose, de esta manera, un mensaje contextualizado y significativo para el estudiante de inglés como lengua extranjera. En las prácticas comunicativas, especialmente en el enfoque metodológico FOCAL SKILLS, la labor del profesor es ayudar al estudiante a alcanzar la adquisición de la lengua extranjera. Para lograr dicho objetivo, es indispensable que los mensajes que ha de entregar en inglés sean comprensibles para el estudiante. Solo así logrará recibir los mensajes en forma eficaz, decodificarlos y responder a ellos, ya sea de forma verbal o no verbal.

\section{FOCAL SKILLS: enfoque metodológico por competencias comunicativas}

De acuerdo a Hastings (2007 [1988])), el enfoque metodológico por competencias comunicativas FOCAL SKILL fue desarrollado en el año 1980 e implementado por primera vez en la Universidad de WisconsinMilwaukee. También ha sido adaptado en otras universidades en Estados Unidos y en el extranjero. Este enfoque consiste en un programa de enseñanza-aprendizaje que asegura una comunicación fluida entre destinador y destinatario, y así permite adquirir segundas lenguas o lenguas extranjeras. Ofrece una estructura lógica que es altamente compatible con las técnicas más efectivas e interesantes para enseñar y adquirir una lengua. Los estudiantes que se encuentran inmersos en programas donde se enseña inglés a través de este enfoque, demuestran un progreso excepcional en los dominios prácticos de la lengua.

Este enfoque se diferencia de otros más tradicionales que potencian el ejercicio forzado y artificial de las estructuras gramaticales, en que involucra a los estudiantes en situaciones lingüísticas y culturales significativas para el aprendizaje, a menudo introducidas por material de carácter auténtico. Con relación a lo anterior, "la adquisición del lenguaje no requiere un uso extenso de reglas gramaticales conscientes 
Evaluación de la puesta en marcha del enfoque metodológico por competencias comunicativas FOCAL SKILLS / Yasna Yilorm y Andrea Lizasoain

ni tediosos ejercicios de repetición" (Krashen, 1987: 6). Por lo demás, este enfoque no espera que los estudiantes hablen inmediatamente; se prioriza la comprensión, fortaleciendo así paulatinamente el proceso de adquisición de una lengua (Hastings, 2007).

\subsection{Características generales del enfoque}

Una de las características esenciales del enfoque metodológico FOCAL SKILLS es el énfasis en la adquisición rápida de la producción práctica, porque las clases son intensivas y se basan en las diferencias individuales de los estudiantes. Una segunda característica es el uso de técnicas para proveer estímulo lingüístico (input) comprensible a través de material audiovisual auténtico y de una versión simplificada del lenguaje (o foreigner talk), mediante el cual se emiten mensajes en forma más pausada, se sube el volumen de la voz y se modula más marcadamente, entre otros (Brulhart, 1986). Otras estrategias comunicacionales que priman en este enfoque son la utilización de imágenes de libros grandes, la actuación, objetos reales y el aprendizaje cooperativo (ESL Resource Center, 2009). Una tercera característica es que se busca crear un ambiente seguro y agradable para el estudiante, que estimule un filtro afectivo bajo (Krashen, 1998), es decir, que disminuya factores emocionales y motivacionales negativos en la sala de clases. Una cuarta característica es la integración progresiva de las cuatro habilidades básicas de la competencia lingüística -escuchar, leer, escribir y hablar-, que implica una integración sistemática y lógica de las habilidades de acuerdo a los avances de los estudiantes y a sus usos potenciales en la sala de clases. Por ejemplo, los estudiantes deben tener una buena comprensión auditiva antes de desarrollar la lectura, escritura y habilidades académicas, y la producción oral debe ser promovida a través de todo el proceso de adquisición de la lengua inglesa, especialmente después de haber alcanzado un buen dominio de la comprensión auditiva. Las pruebas de diagnóstico que incluye este enfoque aseguran que los estudiantes hayan alcanzado un buen dominio de ciertas habilidades antes de focalizarse en otras. En relación a lo anterior, se trabaja con un sistema de módulos centrados cada uno en una habilidad en particular. Cuando las pruebas de diagnóstico arrojan un mínimo de 80\% de aprobación, el estudiante puede pasar al módulo siguiente. Esto permite que el currículo central del enfoque se ajuste a las necesidades y fortalezas de cada uno de los estudiantes: estos no cursan los módulos que no necesitan, pero sí completan los módulos requeridos de acuerdo a sus habilidades, las veces que sea necesario. Una quinta característica de este enfoque está relacionada con la

$+132$


enseñanza creativa: los profesores deben encontrar material interesante y creativo, planificar formas apropiadas de utilizarlo y buscar maneras de presentarlos que resulten efectivas y motivadoras (Global Language Education Services, 2010).

\subsubsection{Metodologías promovidas por el enfoque FOCAL SKILLS}

El Enfoque Natural (Natural Approach) de Krashen y Terrell (1983) y el método Respuesta Física Total (Total Physical Response) de Asher (1974) son prácticas comunicativas que cumplen con los principios básicos del enfoque FOCAL SKILLS y que, por lo tanto, pueden ser utilizados en los módulos de este modelo. El Enfoque Natural sugiere que los estudiantes adquieren la segunda lengua o lengua extranjera de la misma manera que los niños adquieren su primera lengua. En primera instancia, adquieren abundante vocabulario a través de un estímulo lingüístico auditivo permanente que, en el largo plazo, les permitirá hablar correctamente. Se enfatiza la importancia del vocabulario, sugiriendo que una lengua es esencialmente su léxico y que la gramática solo determina de qué manera se aprovecha el léxico para producir mensajes (Richards \& Rodgers, 2001). El significado es la prioridad máxima y la forma de adquirirse es de manera implícita. Los juegos, las canciones, los bailes, las actuaciones, el relato de cuentos, las actividades teatrales, las funciones de títeres, los videos y las actividades de resolución de problemas son componentes cruciales de una clase en la que se aplica el Enfoque Natural. "Los profesores imparten contenidos comprensibles, por medio de una variedad de actividades interesantes que cumplen con las necesidades, habilidades y objetivos de los estudiantes" (Ariza et al., 2002: 231-232). Los cuatro principios básicos de este enfoque son que "la comprensión precede a la producción, la producción debe emerger en etapas (variables), el plan de estudios se concentra en objetivos comunicativos y las actividades se diseñan para bajar el filtro afectivo" (Richard-Amato, 2003: 170), principios que el enfoque FOCAL SKILLS cumple a cabalidad.

Por su parte, el método TPR de Asher (1974) incorpora la comunicación verbal y no verbal entre los profesores y estudiantes. En una primera etapa, los estudiantes decodifican los movimientos y gestos del profesor. A medida que estos se familiarizan con los mensajes entregados, el profesor va proveyendo estímulo lingüístico cada vez más complejo, comenzando siempre por expresiones de tipo imperativo. De esta manera, se espera que el habla surja natural y espontáneamente, una vez desarrollada la comprensión. Este método consiste principal- 
Evaluación de la puesta en marcha del enfoque metodológico por competencias comunicativas FOCAL SKILLS / Yasna Yilorm y Andrea Lizasoain

mente en dar instrucciones a los estudiantes, quienes responden verbal y no verbalmente. "Los estudiantes actúan con el cuerpo y la mente; en otras palabras, con todo su ser" (Richard-Amato, 2003: 158). La fundamentación de este método es que para que cualquier metodología de enseñanza de lenguas extranjeras sea efectiva, debe seguir los tres principios de la adquisición de la primera lengua formulados por Asher en 1982, concretamente, la habilidad auditiva debe desarrollarse antes que el habla, la comprensión se logra observando el lenguaje a través de movimientos corporales y las habilidades auditivas preparan a los aprendices para hablar (Solé, 1987).

Ambos modelos comunicativos se centran principalmente en el estudiante, considerado como un individuo capaz de contribuir a su propio proceso de aprendizaje, a través del auto-descubrimiento, la solución de problemas y la toma de decisiones. Sus necesidades son tomadas en cuenta y los periodos de silencio, al igual que los ritmos de aprendizaje, son respetados. Además, se ofrecen múltiples espacios y oportunidades de interacción para actuar de forma voluntaria.

\section{Metodología del estudio}

5.1. Muestra: este estudio de caso cualitativo y cuantitativo de tipo cuasi-experimental se diseñó para ser llevado a cabo con aproximadamente 125 estudiantes de las carreras de Ingeniería Comercial (grupo experimental) y Auditoría (grupo control) de la Universidad Austral de Chile, que no presentaban las competencias lingüísticas básicas de la lengua inglesa, a través de una investigación-acción. Los estudiantes de Ingeniería Comercial, de primer año, se dividieron en 5 grupos de cerca de 25 estudiantes cada uno, de los cuales 3 participaron en la investigación; y los de Auditoría, de segundo año, en 2 grupos de aproximadamente 25, al principio del primer semestre de 2011. Todos los sujetos eran hablantes nativos del castellano hablado en Chile, cuyas edades fluctuaban entre 17 y 21 años.

5.2. Distribución de los grupos: a comienzos del mes de marzo, se tomó una prueba diagnóstica de comprensión auditiva, escrita y oral, a todos los sujetos del grupo experimental. Según los resultados de la prueba escrita traducidos en notas de 1,0 a 7,0, se formaron 5 grupos, de manera que cada uno tuviera estudiantes con notas entre los grupos 1,0 a 3,0; 3,1 a 4,0; 4, 1 a 5,0; 5,1 a 6,0; y 6,1 a 7,0. En el caso del grupo de control, se aprovechó la distribución institucional del curso en dos grupos (Grupo A y Grupo B), que normalmente se hace alfabéticamente.

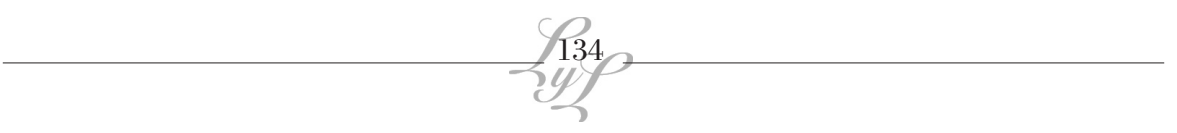


5.2.1. Grupo experimental: después de la prueba de diagnóstico, los estudiantes de este grupo fueron expuestos al módulo de comprensión auditiva del enfoque comunicativo FOCAL SKILLS por dos meses, cerca de 20 horas pedagógicas. Durante este periodo, los sujetos recibieron una cantidad de estímulo lingüístico oral importante a través de canciones, películas, conversaciones, entrevistas en inglés, entre otros. Además, experimentaron actividades lúdicas y culturales a través de las cuales se vieron expuestos a distintas formas gramaticales de manera implícita. En ninguna ocasión se les enseñaron estructuras gramaticales ni vocabulario de manera explícita durante estas 20 horas.

5.2.2. Grupo control: el grupo control no tuvo prueba de diagnóstico y durante las mismas 20 horas de clase fue expuesto a metodologías más tradicionales basadas en textos de estudio, como el New Headway de Oxford University Press, y en guías de gramática básica y de vocabulario instrumental para complementar, según lo informado por uno de los profesores responsables del curso. Es decir, las estructuras gramaticales y el vocabulario se estudiaron de manera explícita durante este periodo.

En resumen, el tratamiento (o variable independiente) aplicado al grupo experimental consistió en la ejecución del módulo de comprensión auditiva del enfoque FOCAL SKILLS, mientras que el grupo control trabajó con materiales tradicionales: ejercicios de gramática y vocabulario explícitos.

5.3. Diseño del material: el instrumento didáctico utilizado en el módulo de comprensión auditiva FOCAL SKILLS al que se vio expuesto el grupo experimental consistió principalmente en materiales audiovisuales auténticos, materiales multi-sensoriales y en las últimas clases, se incorporó el texto de estudio World Link I (2001). El material audiovisual consistió primariamente en entrevistas a personas famosas, encuentros entre personas comunes y corrientes en la calle, extraídas del programa de videos Real English, canciones con karaoke para cantar y bailar, películas, documentales y reportajes, mientras que el material multi-sensorial comprendió el uso de realia, juegos didácticos, autoadhesivos y tarjetas de saludo y reconocimiento, entre otros. El único elemento artificial que se tuvo que incluir hacia el final de las 20 horas de aplicación de la versión adaptada del módulo de comprensión auditiva -por políticas internas de la unidad donde se aplicó el enfoque- es el texto de estudio antes mencionado. Este ofrece ejercicios de aplicación e interacción entre los estudiantes, pero, a su vez, presenta la gramática en forma explícita. Sin embargo, se planeó el trabajo con el libro de tal 
Evaluación de la puesta en marcha del enfoque metodológico por competencias comunicativas FOCAL SKILLS / Yasna Yilorm y Andrea Lizasoain

manera que aquellos ejercicios gramaticales se realizaran en la casa más bien para reforzar conocimientos.

5.3.1. Prueba de diagnóstico (pre-test): la batería de pruebas de medición de competencias consistió en tres instancias fundamentales: una prueba de comprensión auditiva basada en el enfoque FOCAL SKILLS, una prueba escrita redactada por el Centro de Idiomas y una prueba oral diseñada por la investigadora principal. La prueba auditiva consistió en 60 ejercicios de selección múltiple para discriminar información proveniente de conversaciones cotidianas obtenidas del sitio web ESL Lab. La prueba escrita contenía ejercicios de gramática explícita de selección múltiple, llenado (completion) de párrafos con léxico, preguntas de comprensión de lectura y redacción de un párrafo. Por último, la prueba oral constó de un ejercicio de calentamiento (warm-up), una sección de preguntas y respuestas simples y directas, una sección de preguntas abiertas, una parte de interacción entre los dos evaluados y, finalmente, la descripción de una fotografía.

5.3.2. Pruebas de medición de avances (post-test): se aplicó un promedio de tres pruebas pequeñas (quizzes) de avance diseñadas con conversaciones extraídas del sitio web ESL Lab en las que los estudiantes discriminaban información mediante alternativas durante todas las semanas. Además, hacia el final de las 20 horas de implementación del módulo, se aplicó una prueba de mediados de semestre para medir el avance general.

\section{Resultados}

En este estudio, se buscaba comparar los resultados de adquisición de la lengua inglesa obtenidos con el enfoque FOCAL SKILLS y metodologías más tradicionales, basadas en la enseñanza de la gramática explícita, a través del uso de libros de texto y guías de apoyo con ejercicios gramaticales y de léxico. Pese a que a través de la observación en el aula por parte de los investigadores y de las notas obtenidas por los estudiantes se vio una mejora notoria en las competencias lingüísticas de estos, no se pudieron obtener resultados estadísticos significativos, debido a las razones que se indican a continuación, ordenadas según su relevancia:

- Por causas administrativas, la institución patrocinante se vio en la necesidad de modificar las condiciones para la implementación de la investigación, una vez que esta ya había comenzado, lo que llevó a cambiar, después de un mes de aplicación del método, el grupo

$+136$


control. Concretamente, una parte de este grupo se convirtió en parte del grupo experimental un mes después, lo que implicó que no estuviera expuesta a la variable independiente (enfoque FOCAL SKILLS), por el mismo tiempo que el grupo experimental original.

- Por otro lado, los estudiantes del grupo control, al no tener una obligación de asistencia a clases con los investigadores, no concurrieron a la toma de prueba de diagnóstico en las tres oportunidades en que fueron citados.

- Además, por las mismas razones administrativas, se agregaron dos grupos más al grupo control, los cuales nunca tomaron la prueba de diagnóstico.

Las tres razones antes descritas, por una parte, invalidaron los resultados estadísticos que podrían haberse obtenido y, por otra, llevaron a la investigadora principal a tomar la decisión de detener el proceso de investigación para replanteárselo.

\subsection{Otros obstáculos}

Además de los principales obstáculos mencionados en el punto anterior, se pueden agregar los siguientes: la aplicación de instrumentos de evaluación (pruebas de diagnóstico, pruebas de avance, encuestas, etc.) y el diseño y adquisición del material didáctico auténtico y multi-sensorial, entre otros, implica un alto costo para el investigador, en términos de tiempo. En segundo lugar, la búsqueda y adaptación de material auténtico implica un alto costo en términos de tiempo y dedicación por parte de los investigadores. En tercer lugar, se requiere una infraestructura específica para la aplicación del enfoque, que incluya salas amplias, con iluminación y acústica adecuadas, y con tecnología de punta, elementos con los que no siempre se contó.

\section{Reflexiones en torno a los resultados y obstáculos}

Si bien todos los obstáculos encontrados en la ejecución de esta adaptación del módulo de comprensión auditiva FOCAL SKILLS fueron determinantes para suspenderla, no constituyen impedimentos que no se puedan superar al replantearse la implementación de dicha investigación en otro establecimiento educacional, siempre y cuando su diseño contemple una gestión y coordinación óptimas de las actividades. Resulta, además, imprescindible contar con la colaboración de las máximas autoridades para facilitar, en primer lugar, la recopilación de datos, tales como la 
Evaluación de la puesta en marcha del enfoque metodológico por competencias comunicativas FOCAL SKILLS / Yasna Yilorm y Andrea Lizasoain

aplicación de baterías de pruebas, de encuestas, cuestionarios y grupos de discusión, así como también asegurar la asignación de las salas de clase más apropiadas para la implementación del enfoque, en términos de amplitud y equipamiento tecnológico. Cabe también resaltar que es indispensable solicitar a las autoridades documentos escritos, donde queden notificados todos los acuerdos, para que no surjan modificaciones en el camino que puedan afectar los datos de la investigación en curso. En su conjunto, estas medidas asegurarán que la aplicación se desarrolle de acuerdo a lo establecido en el diseño original de la investigación y contar, a su vez, con el compromiso de quienes dirigen y participan en la institución patrocinante.

A pesar de los múltiples obstáculos encontrados a lo largo de esta investigación-acción, en el presente artículo se sostiene que la práctica comunicativa FOCAL SKILLS sigue siendo una metodología viable, capaz de brindar a los estudiantes chilenos las herramientas necesarias para empezar a comunicarse en inglés en forma comprensible. La primera aplicación de prácticas comunicativas en el área de inglés de la Universidad Austral de Chile en el año 2007 arrojó que los estudiantes, en su mayoría, valoran las innovaciones metodológicas como estrategias entretenidas, motivadoras y efectivas en términos de adquisición de la lengua extranjera; además, destacan como elemento generador de aprendizaje y de motivación fundamental el uso variado de material didáctico multisensorial y auténtico y, por otra parte, valoran sobremanera la actitud positiva del profesor en la sala de clase, lo que, a su juicio, promovió un clima de confianza que les permitió expresarse libremente en la lengua extranjera sin sentir temor. Apoyando los cambios metodológicos en la sala de clase, los estudiantes sostuvieron lo siguiente: "Me gustaron las clases didácticas, no son aburridas como las otras clases de inglés donde fundamentalmente se enseña pura gramática". "La clase de inglés fue muy entretenida y didáctica, fue muy agradable venir a clases puesto que había motivación" y "La metodología me hizo perder el miedo a hablar, a equivocarme y aprendí bastante", entre otros comentarios positivos extraídos de los cuestionarios aplicados el año 2007. De igual manera, los cuestionarios de opinión aplicados a los 125 estudiantes de Ingeniería Comercial expuestos a esta versión del módulo de comprensión auditiva también confirman la aceptación del enfoque por parte del alumnado. $\mathrm{Al}$ respecto, véanse los siguientes comentarios de tres estudiantes: "Me encantó la forma de trabajar de la profesora con los alumnos, porque ella no estaba detrás de un escritorio sino que trabajando y haciendo clases muy didácticas con sus alumnos, dándonos mayor seguridad de poder participar de las clases". "Comparando estas clases de inglés

$+138$


con las que tenía en el colegio, las de la universidad son mucho más divertidas, por lo tanto, me permitieron aprender de mejor manera los contenidos”. Finalmente, “... la forma de enseñar de la docente hacía parecer fácil cualquier cosa, las clases eran entretenidas, lo cual motiva para asistir a cada una de ellas y así poder involucrarse un poco más con este idioma". Estas opiniones reflejan los principios básicos de la adquisición de una lengua extranjera en el marco de la comunicación efectiva entre el destinador (profesor) y el destinatario (alumno), ya que mediante prácticas motivadoras y entretenidas que incluyen actividades metodológicas diversas, material didáctico atractivo, un ambiente de aprendizaje favorable, entre otros aspectos positivos, los estudiantes se relajan, se interesan y se olvidan de que se encuentran en una sala de clase, y por ende, adquieren las competencias comunicativas de la lengua extranjera en forma natural.

En términos cuantitativos, la aplicación de la versión adaptada del módulo de comprensión auditiva aplicada a los estudiantes de la carrera de Ingeniería Comercial de primer año de la Universidad Austral de Chile, durante los meses de marzo y abril del primer semestre del año 2011, demuestra que un 95,8\% de los estudiantes mejoró su nivel de comprensión auditiva, si comparamos los puntajes de entrada obtenidos a principio del mes de marzo del 2011 con la prueba de cátedra que se realizó en el mes de mayo del 2011. Además, cabe resaltar que el 62,5 $\%$ de los estudiantes obtuvo una nota igual o superior a 5,6, siendo esta una nota que indica dominio de competencias de acuerdo al enfoque FOCAL SKILLS; al ingresar a la universidad, solo el 2,16\% había obtenido una nota igual o superior a 5,6.

Dados los resultados anteriores, esta investigación-acción se replanteará como una alternativa metodológica que también es aplicable al contexto educacional básico en colegios públicos chilenos, con el objetivo de comprobar la hipótesis sostenida: el enfoque FOCAL SKILLS desarrollado por Hastings en 1988 (Hastings, 2007) asegura la adquisición de la lengua extranjera en forma más efectiva y rápida que los métodos más tradicionales.

\section{Conclusiones}

Debido al impacto económico, social, cultural y tecnológico de la globalización experimentado durante las últimas décadas en Chile, los procesos de enseñanza-aprendizaje del inglés como lengua extranjera ya no pueden mantenerse al margen de los cambios metodológicos requeridos para 
Evaluación de la puesta en marcha del enfoque metodológico por competencias comunicativas FOCAL SKILLS / Yasna Yilorm y Andrea Lizasoain

responder a las necesidades reales de nuestros estudiantes del siglo XXI, quienes requieren, con urgencia, adquirir habilidades lingüísticas que les permitan comunicarse en inglés. Consecuentemente, "la competencia comunicativa" constituye el objetivo principal de toda clase de inglés comprometida con los cambios sociales.

Dicha competencia comunicativa solo puede ser alcanzada si existe un modelo de comunicación que asegure la entrega clara y fluida de un mensaje, y por ende, una recepción y asimilación positivas que, a su vez, permitan la continuación de dicho proceso comunicativo en forma efectiva. Este artículo propone el modelo de comunicación de Jakobson para alcanzar dicho objetivo, por cuanto promueve el principio más importante del proceso de adquisición de una lengua extranjera: que los mensajes enviados a los estudiantes sean lo suficientemente comprensibles para que puedan responder a ellos espontánea y naturalmente. De esta manera, en este enfoque, se destaca la función poética de dicho modelo, por la gran cantidad y diversidad de material auténtico que proveen mensajes reales y más comprensibles para los destinatarios.

El modelo FOCAL SKILLS cumple a cabalidad con los principios básicos de un proceso de adquisición efectivo de una segunda lengua o lengua extranjera. En primer lugar, al comenzar por el módulo de habilidad auditiva, se respeta el periodo de silencio necesario para el desarrollo de la comprensión de la lengua. En segundo lugar, se respetan los ritmos individuales, ya que los estudiantes trabajan a su propio paso y son ubicados en los diferentes módulos según sus competencias. En la sala de clases, los profesores proveen un ambiente de adquisición favorable, positivo, seguro y profesional, donde los estudiantes se sienten cómodos porque son respetados como seres humanos en proceso de aprendizaje. Además, el rol facilitador del profesor es positivo y contribuye altamente a concretar el proceso de adquisición de la lengua, ya que este se esfuerza por entregar a los estudiantes mensajes comprensibles y contextualizados a través de técnicas y materiales didácticos entretenidos e interesantes. Por otra parte, estos son siempre estimulados a participar en actividades de carácter comunicativo que les permitan producir efectivamente. Es así como los estudiantes logran adquirir la lengua en forma inconsciente y natural.

Si bien la aplicación de una versión adaptada del módulo de comprensión auditiva FOCAL SKILLS, en los estudiantes de primer año de la Escuela de Ingeniería Comercial de la Universidad Austral de Chile, no pudo concretarse a cabalidad, debido a la intervención de obstáculos

$+200$


de carácter administrativo, el avance de los estudiantes, en términos de adquisición de la lengua inglesa, es notorio. Por otra parte, la exposición de los estudiantes a un input auditivo importante, a través del uso de material didáctico auténtico y multi-sensorial, constituye efectivamente un requisito primordial para que los estudiantes produzcan la lengua extranjera a un nivel básico pero en forma fluida y comprensible, cumpliéndose así el dominio de la competencia comunicativa.

\section{Bibliografía}

Arcos, L. y Poblete, R. (2009). Interview to Andrew Sheehan. Comunicación personal inédita.

Ariza, E., Morales-Jones, C., Yahya, N., Zainuddin, H. (2002). Why TESOL? Theories and Issues in Teaching English as a Second Language with a K-12 Focus, 2a edición. Boca Raton, Florida: Kendall Hunt Pub Co.

Brown, D. (2007). Principles of Language Learning and Teaching. Nueva York: Pearson.

Brulhart, M. (1986). Foreigner Talk in the ESL classroom: Interactional Adjustments to Adult Students at Two Language Proficiency Levels. Recuperado de http://www. teslcanadajournal.ca/index.php/tesl/article/ viewFile/992/811

Canale, M. y Swain, M. (1980). Theoretical Bases of Communicative Approaches to Second Language Teaching and Testing. Applied Linguistics 1, 1-47.

CENTRO DE IDIOMAS DE LA UNIVERSIDAD AUSTRAL DE CHILE, 2010: Base de datos 2010.

Chomsky, N. (1965). Aspects of the Theory of Syntax. Cambridge: The MIT Press.

EducarChile (2011). Resultados Simce Inglés 2010. Recuperado de http:// www.educarchile.cl/Portal.Base/Web/VerContenido. aspx? ID=208390

ESL Resource Center (2009). 15 Simple Ways to Increase Comprehensible Input. Recuperado de http://www.planesllessons. com/2009/01/15-simple-ways-to- increasecomprehensible-input/ 
Evaluación de la puesta en marcha del enfoque metodológico por competencias comunicativas FOCAL SKILLS / Yasna Yilorm y Andrea Lizasoain

Galloway, A. (1993). "Communicative Language Teaching: An Introduction and Sample Activities". Recuperado de http://www. cal.org/resources/digest/gallow01.html

Global Language Education Services (2010). "The FOCAL SKILLS Approach". Recuperado de http://www.focalskill.info.html

González, J. L. (2000). Variables de la educación en comunicación. En Pérez, J.M. (Ed.), Comunicación y educación en la sociedad de la información. Nuevos lenguajes y conciencia crítica. Barcelona: Ediciones Paidós Ibérica, S.A.

Hastings, A. y B. Murphy (2002). Thoughts on the use of authentic material. Recuperado de http: //www.focalskills.info/articles/ authentic.html

Hastings, A. (2007). Proposal for Consulting Services to be performed by Global Language Education Services, Inc. for Universidad Austral de Chile, manuscrito no publicado.

Jakobson, R. y Halle, M. (1967). Fundamentos del lenguaje. Madrid: Editorial Ciencia Nueva, S.L.

Krashen, S. (1985). The Input Hypothesis. Issues and Implications. Torrance, CA: Laredo Publishing Co.

(1987). Principles and Practice in Second Language Acquisition. USA: Prentice-Hall International.

(1998). Second Language Acquisition and Second Language Learning. London: Prentice-Hall International.

La Nación. (2011, 4 de noviembre). Simce Inglés. Recuperado de http://www.lanacion.cl/simce-de-ingles-solo-fueaprobado-por-el-11-por-ciento-de-los-alumnos/ noticias/2011-03-24/131126.html

Ministerio de Educación (2004). Resultados nacionales del diagnóstico en inglés. Recuperado de http://www.simce.cl/fileadmin/ Documentos_y_archivos_SIMCE/biblioteca/ingles. pdf

Omaggio, A. (2001). Teaching Language in Context. USA: Heinle \& Heinle.

Pérez, J. M. (2000). Las escuelas y la enseñanza en la sociedad de la información. En Pérez, J.M. Comunicación y educación en la sociedad de la información. Barcelona: Ediciones Paidós Ibérica, S.A. 
Rababah, G. (2002). Strategic Competence and Language Teaching. Recuperado de http://www.eric.ed.gov/PDFS/ ED472697.pdf

Richard-Amato, P. (2003). Making it Happen. From Interactive to Participatory Language Teaching. Theory and Practice, tercera edición. White Plains, NY: Pearson Education.

Richards, J. y Rodgers, T. (2001). Approaches and Methods in Language Teaching, 2a edición. Cambridge: Cambridge University Press.

Rodrigo Alsina, M. (1995). Los modelos de comunicación, segunda edición. Madrid: Editorial Tecnos, S.A.

Segal, B. (2006). What is TPR? Recuperado de http://www.tprsource.com/ asher.htm

Sierra, F. (2002). Comunicación, educación y desarrollo. Apuntes para una historia de la comunicación educativa. Sevilla: Comunicación Social Ediciones y Publicaciones.

Solé, M. (1987). Total Physical Response: an Approach to Teaching Foreign Languages. Methodological Criteria and Empirical Evidence. Anuari D’Anglès X, 89-103.

Van Dijk, T. (2008). Discourse and Context.Cambridge: Cambridge University Press.

Yano, Y. (s.f.). Communicative competence and English as an international language. Recuperado de http://www.paaljapan.org/ resources/proceedings/PAAL7/pdfs/03yasukata.pdf 